\title{
Performance Evaluation of Selected Banking Stocks Listed on Bombay Stock Exchange During Pre \& Post Covid-19 Crisis
}

\author{
${ }^{1}$ Dr.Vishal Kumar \\ ${ }^{2}$ Ritu Rani
}

${ }^{1}$ Director, School of Management \& Dean Research, Maharaja Agrasen University, India
2Research Scholar, School of Management, Maharaja Agrasen University, India

\begin{abstract}
Investing in the stock market has always been regarded as risky. Market sentiment is a factor that influences stock prices. The purpose of this study is to assess the performance of selected banking stocks based on risk and excess return generated by them during the study period. The study also determines the effect of certain financial variables on sample banking stocks during the time crisis of Covid'19. Economic variables such as the BSE Sensex, rate of exchange, variation in FII (Foreign Institutional Investors), and coupon rate of Government Sector (G-Sec) were analysed in conjunction with the analysis of banking stocks. The regression and correlation tests are used to determine the significance of variables using SPSS. Following the BSE's performance provides insight into the future modifications throughout the price levels of bank shares. Following a sharp decline in the market, private sector bank stock prices are correct, but not public sector bank stock prices. Throughout the first part of the research, there is a direct relationship between the BSE, Sensex, and the selected stocks, but only a weak correlation with FII, G-Sec coupon rate, and the exchange rate. Along the second part of the research, the relationship between stock prices and economic variables varies widely between banks.
\end{abstract}

Keywords: Fluctuating Returns, FII, G-Sec Rate, Exchange Rate, Financial Sector, Bombay Stock Exchange, Covid'19

\section{Introduction}

The banking sector is often called as the economy's backbone because it is critical to economic development and provides economic reservoirs by individuals, business owners, and sectors in need. Because banking is the core of the business, the banking sector is critical to the smooth operation of all sectors. This sector's financial stability is inextricably linked to the growth of the economy. By pooling individual savings and lending them to needy sectors, the banking sector facilitates commerce. The business borrows money to meet its working capital requirements and to acquire additional assets. This process generates a two-tier benefit for the economic system by collecting idle money and reinvesting it in productive activities. As a result, the country gains new capital assets. A healthy financial system is critical for financial self-dependence and sustained GDP growth. Covid'19, the globally spread pandemic, has struck the country when India's economy has already slowed to its lowest level in a decade. Economic activity has ceased. As the economy's backbone, the banking sector stepped forward to lend a helping hand to a few sectors. The RBI cut 'repo rates' to promote liquidity and money circulation in the economy. Additionally, the central bank announced loan repayment relief. Investing in the stock market has always been regarded as risky. Stocks do not guarantee a higher return at all times. Stock prices fluctuate due to the market's production and consumption of shares. Negative sentiments may result in an unexpected price fluctuation in the event of an unforeseen circumstance. Narayan et al. (2014) evaluated the components of stock prices for main Indian banks using panel data modelling techniques and they discovered a link between investment activity, interest rates, currency exchange rates, and bank stock prices. According to their research, a rise in interest rates decreases in bank stock values, 


\section{Dr. Vishal Kumar, Ritu Rani}

Performance Evaluation of Selected Banking Stocks Listed on Bombay Stock Exchange During Pre \& Post Covid-19 Crisis

whilst economic growth and currency depreciation result in a price increase. Tripathi and Ghosh (2012) examined the impact of interest rates on banking stock returns in India and discovered a weak negative correlation between interest rates and bank stock returns. J. Loomba (2012) developed a strong, meaningful correlation between share prices and FII activity in the Indian economy. The findings of various research studies on banking stock piqued the researcher's interest in the relationship between banking shares and macroeconomics factors during times of crisis, as very little research was available on the period immediately following the government's declaration of lockdown due to Covid'19.

\section{Literature Review}

Investors' behaviour is frequently disturbed by disasters, which can eventually affect their stock selection decisions. Fama et al. (1969) conducted an innovative event study that demonstrating that stock price volatility is associated with different events. The existing literature concentrated primarily on natural catastrophes, terror acts, political behaviour, and financial crises, focusing on the role between catastrophes and stock prices. Kalra, Henderson, and Raines examined the Soviet nuclear plant disaster. According to Nikkinen et al. (2008), the "911" incident had a major impact on future stock prices, which then improved. Al-Rjoub (2011) and Al Rjoub and Azzam (2009) examined the Mexican tequila crisis of 1994, the financial crisis of 1997-1998, the Iraq war of 2004, the financial crisis of 2005, and the global financial crisis of 2008-2009. (2012), these authors examined if these periods affect the Jordan Stock Exchange's stock compensation behaviour. Schwert. (2011) examined how US stock prices fluctuated and during the financial crisis. Lanfear, Lioui and Siebert (2018) discovered that catastrophes affecting consumer growth can affect the stock market. Yin, Lu, and Pan (2020) investigated the effects of the Sino-US trade war on the Chinese Stock markets and discovered that terrible experiences have a longer-lasting effect on prices than positive ones. Covid'19 has a significant and enduring negative effect on the world economy. 2020 (Iyke). Narayan and Phan investigate the impact of Covid'19 upon on share market as well as the responses of countries (2020), there are narrow studies on the role of Covid'19 on share prices in the published studies, and there are few studies on the role of financial factors on bank shares during governmentannounced lockdown immediately following that period. Qin et al. (2020) examined the pandemic's impact on oil markets. Ali, Alam, and Rizvi (2020) examined the impact of COVID-19 on a variety of financial instruments and made comparisons between China and other countries. In this context, we examined the various changes in the banking sector's stock prices during the pandemic period. Sunil Rashinker (2014) conducted a risk analysis of nationalised banking stocks. The results of this work established that few bank stock prices increased during unfavourable market conditions that raised the question of whether market conditions always have the same effect on company stock prices. Shaini Naveen and T. Mallikarjunappa (2016) discovered that all banks have favourable beta value and that the stock prices of a few banks move in the opposite direction of the market. According to a recent study by P. Naveen and K. Neeraja (2018) among the banks studied, HDFC bank achieved the greatest returns and the lowest risk. Patjoshi, P. (2016) examined the risk-return of the Indian Banking sector over 15 years and discovered a significant positive correlation between the Sensex and banking stocks, except ICICI bank returns. Singh and Makkar (2014) used the GARCH model to evaluate the relation between crisis and share prices in the Indian banks. Their study found a substantial negative relationship between the price of banking stocks and their volatility during the crisis. Further research by J Cave, K Chaudhuri, and SC Kumbhakar (2020) discovered a negative correlation between financial development and economic growth. However, the stock market had a positive effect on economic growth up to a point, after which the effect shifted to the negative and this effect raised further queries in the researcher's mind about the validity of the same findings and during the current Covid'19 economic crises.

2.1 Research Objectives: This research paper aims to achieve the following objectives:

- To analyse and assess the risk and return of selected five banks listed on the Bombay Stock Exchange.

- To Study the volatility of the selected banking and examine the effect of fluctuations of monetary factors on banking stocks pre-covid'19 and post-covid'19. 


\section{Research Methodology}

The research methodology comprises the plan which determines the tools, techniques, methods, and procedures followed to collect, analyse and interpret the data to achieve the research objectives. The research design used for the present study is descriptive.

\subsection{Sample Selection}

To examine the performance of the selected banking stocks before and after the Covid19 crisis, a sample of the top five banks based on the market capitalisation was drawn using the technique of judgmental sampling. All the banks are listed on the Bombay Stock Exchange. These banks are being selected for this research study based on the rigorous competition exists presently between these five stocks due to the similar nature of services being offered to the public.

\subsection{Period of the Study \& Sources of Data Collection}

The study uses secondary data to examine the share prices of chosen banks pre and post-March, 2020, i.e. from April 2019 to March 2020 and April 2020 to March 2021. This study period was chosen to estimate the impact of the disease outbreak crisis on bank stock prices before and on following day when the crisis's impact was most perceived on the share market. Bank stock prices were retrieved from yahoofinance.com, exchange rates and G-sec rates were retrieved from the RBI Bulletin and investing.com, and the FII movement was retrieved from the RBI Bulletin and moneycontrol.com. Beta and unusual returns have been determined by calculating each bank share price over these two years to determine the fluctuation and differentiation in the stock prices over the chosen period. Correlation analysis was used to determine the relationship between bank stock prices and selected economic variables. Moreover, the share prices of the selected banks have been reverted against economic variables to ascertain the effect of their changes on the bank stocks. SPSS software was used to conduct the statistical analysis. The tools used for analysis are Mean Deviation, Beta, Correlation, Regression, Abnormal Return.

\section{Data Analysis and Interpretation}

5.1. This section calculates the standard deviation of share prices from the mean. It illustrates the price dispersion around the average price over the period. The table below shows the deviation value.

Table 1: Showing the Mean Deviation of Selected Stock Prices Before \& After Pandemic

\begin{tabular}{|c|c|c|}
\hline Name of the Bank & $\begin{array}{c}\text { Mean Deviation } \\
\text { Before Covid'19 }\end{array}$ & $\begin{array}{c}\text { Mean Deviation } \\
\text { After Covid'19 }\end{array}$ \\
\hline HDFC Bank & 0.026 & 0.04 \\
\hline State Bank of India & 0.042 & 0.031 \\
\hline Kotak Mahindra & 0.029 & 0.044 \\
\hline ICICI Bank & 0.031 & 0.052 \\
\hline Axis Bank & 0.033 & 0.059 \\
\hline
\end{tabular}

HDFC Bank has the lowest stock price deviation during the first half of the cycle, and SBI bank has the highest during the second half of the period. In contrast, SBI and Axis bank has the highest during the first and second halves of the period, respectively.

\section{Abnormal Returns \& Beta Value}

This section examines the uncertainty of the shares of selected banks about the BSE index throughout the two years data collection period. Additionally, it evaluates the volatility in 
Dr. Vishal Kumar, Ritu Rani

Performance Evaluation of Selected Banking Stocks Listed on Bombay Stock Exchange During Pre \& Post Covid-19 Crisis

returns during this period to determine if the price has rectified itself following its low in March 2020. The table below details the beta and volatility in returns of each bank.

Table 2: Showing the Abnormal Returns and Beta Value of Selected Five Stocks

\begin{tabular}{|c|c|c|c|}
\hline \multirow{2}{*}{ HDFC Bank } & Beta & 0.78 & 1.3 \\
\cline { 2 - 4 } & Abnormal Return & $-2.17 \%$ & $1.90 \%$ \\
\hline \multirow{2}{*}{ State Bank of India } & Beta & 0.98 & 1.05 \\
\cline { 2 - 4 } & Abnormal Return & 1.03 & $-0.97 \%$ \\
\hline \multirow{2}{*}{ Kotak Mahindra Bank } & Beta & 0.88 & 1.27 \\
\cline { 2 - 4 } & Abnormal Return & $-1.25 \%$ & $1.70 \%$ \\
\hline \multirow{2}{*}{ ICICI Bank } & Beta & 1.05 & 1.67 \\
\cline { 2 - 4 } & Abnormal Return & $-0.64 \%$ & $3.81 \%$ \\
\hline Axis Bank & Beta & 1.09 & 1.59 \\
\cline { 2 - 4 } & Abnormal Return & $0.66 \%$ & $3.60 \%$ \\
\hline
\end{tabular}

Interpretation: By examining the beta, it is clear that the beta analysis of a chosen stock price demonstrates that bank stocks are pretty unstable during a crisis. This instability in stock price is due to the crisis's effect on the economy, which has a direct impact on the banking services industry and thus on profitability. For SBI, the abnormal returns are positive during the pre-lockdown period because the actual return exceeds the expected return. Still, it becomes negative as stock prices fall below the expected level. For Kotak Mahindra Bank, HDFC Bank, ICICI Bank, and AXIS Bank, the abnormal return was negative in the pre-period due to actual negative returns due to falling prices. The post-period positive abnormal return shows that the data has recovered from the previous fall. The most significant clarification is shown in the price levels of ICICI and AXIS banks, which has risen by more than $3 \%$.

\subsection{Correlation Analysis}

The section examines the relationship between certain bank stocks and economic variables. This enables us to determine whether the movement in stock prices corresponds to the direction of the underlying variables, such as the BSE Sensex, exchange rate, FII movement, and G-Sec rate. The table below illustrates the co-relation coefficient's values before and following the lockdown.

Table 3: Showing Correlation Between Selected Stocks Prices and Various Economic Variables Pre-Lockdown

\begin{tabular}{|c|c|c|c|c|}
\hline Bank & $\begin{array}{c}\text { BSE } \\
\text { Sensex }\end{array}$ & Exchange Rate & FII Movement & $\begin{array}{c}\text { G-Sec Coupon } \\
\text { Rate }\end{array}$ \\
\hline HDFC Bank & 0.97 & -0.87 & 0.65 & 0.24 \\
\hline State Bank of India & 0.95 & -0.91 & 0.68 & 0.28 \\
\hline Kotak Mahindra Bank & 0.94 & -0.77 & 0.59 & 0.3 \\
\hline ICICI Bank & 0.97 & -0.85 & 0.66 & 0.17 \\
\hline Axis Bank & 0.01 & -0.87 & 0.66 & 0.19 \\
\hline
\end{tabular}

Interpretation: The relationship between the BSE and bank stocks demonstrates that the correlation coefficients for all banks are greater than 0.9 , indicating a very strong correlation. A related trend was observed in the relationship between the Sensex and bank stocks, which are inextricably linked. Throughout the period, there is a significant negative relationship between bank shares and the rate of exchange. This relationship demonstrates during an emergency, the stock price and the exchange rate move in the opposite direction. The FII and bank stock movements have a moderate correlation. ( 0.5 to 0.7 ) It indicates that changes in FII activity cause changes in stock prices, but the magnitude is moderate. The correlation between the G-Sec level and bank stocks is less than 0.3, indicating a very weak relationship. Shifts within G-Sec rates may have a less dramatic effect on stock prices. 
Dr. Vishal Kumar, Ritu Rani

Performance Evaluation of Selected Banking Stocks Listed on Bombay Stock Exchange During Pre \& Post Covid-19 Crisis

Table 4: Showing Correlation Between Selected Stocks Prices and Various Economic Variables Post-Lockdown

\begin{tabular}{|c|c|c|c|c|c|}
\hline Bank & BSE & Sensex & $\begin{array}{c}\text { Exchange } \\
\text { Rate }\end{array}$ & FII Movement & $\begin{array}{c}\text { G-Sec Coupon } \\
\text { Rate }\end{array}$ \\
\hline HDFC Bank & 0.83 & 0.87 & -0.12 & 0.36 & -0.37 \\
\hline State Bank of India & -1.3 & -1.8 & 0.22 & -0.14 & 0.12 \\
\hline Kotak Mahindra Bank & 0.14 & 0.21 & -0.39 & 0.13 & 0.14 \\
\hline ICICI Bank & 0.66 & 0.7 & -0.03 & 0.2 & -0.33 \\
\hline Axis Bank & 0.72 & 0.73 & -0.23 & 0.16 & -0.53 \\
\hline
\end{tabular}

Interpretation: When BSE and bank stocks are compared, HDFC bank and AXIS bank have a strong correlation, while ICICI bank has a moderate correlation. Kotak Mahindra Bank has a weak correlation. SBI bank has a negative correlation, indicating that no correction in the market occurred during the post period. This relationship is also evident in the abnormal return analysis, which shows that some banks show favourable volatility in the post-period, while SBI has a lower impact. On returns. The Sensex follows the same trend as the Nifty, with SBI having a negative correlation, Kotak Mahindra bank having a weak correlation, and HDFC, ICICI, and AXIS bank having a positive correlation. When bank stocks exhibit a post-period correlation with the exchange rate, there is a negative correlation found between Kotak Mahindra Bank and HDFC Bank and a slight decrease in correlation between the remaining three banks. Apart from SBI, where a negative relationship can be observed, FII movement during the post-period has a low correlation with bank stocks. The GSec coupon rate has a low relationship with SBI and Kotak Mahindra Bank in the post-period. The graph given below portrays the above-explained relationship.

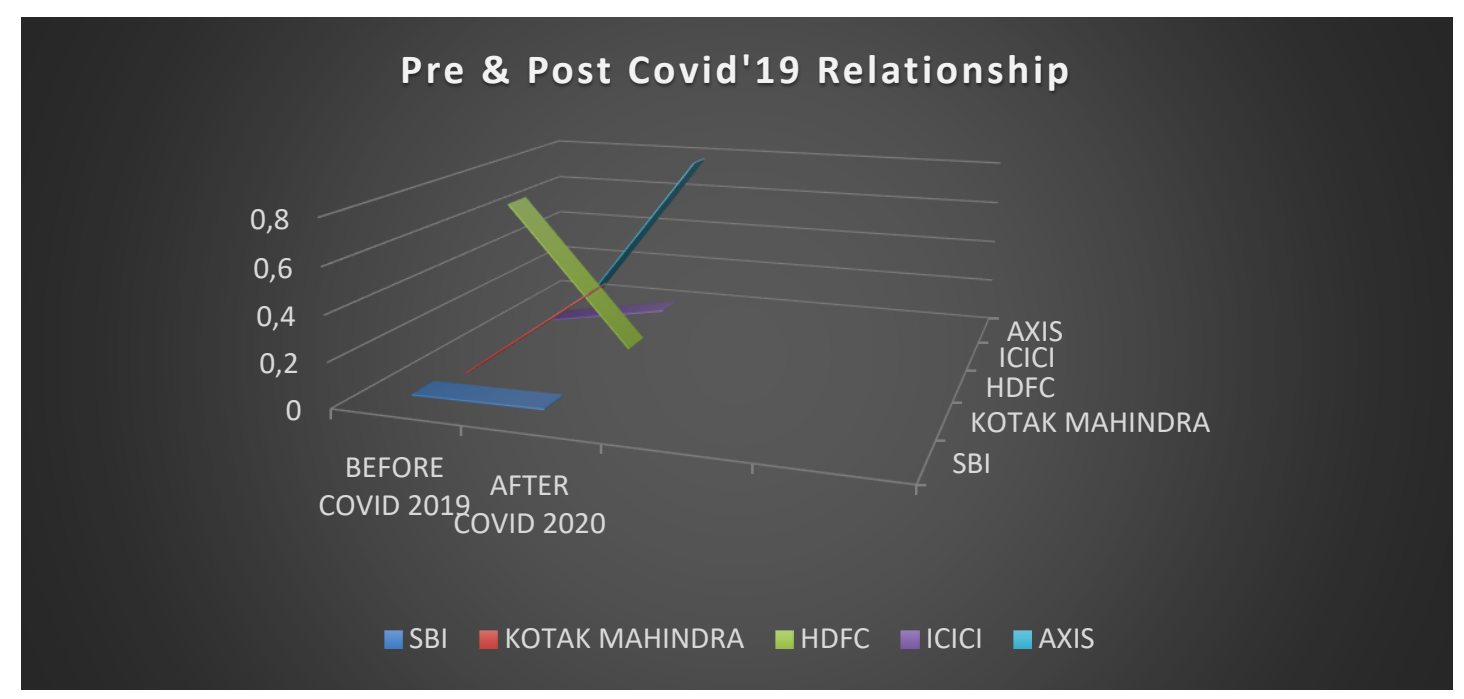

\subsection{Regression Analysis}

This section determines whether the impact on macroeconomic variables chosen have an effect on the bank stocks chosen. Daily bank stock prices were tracked for the chosen period of 2019 and 2020 then regressed against the rates of selected factors during that period to determine the impact.

Table 5: Showing the Regression Values of Selected Stocks Returns with BSE Sensex Returns

\begin{tabular}{|c|c|c|}
\hline Bank & Pre-Covid'19 & Post Covid'19 \\
\hline HDFC Bank & 0.07 & 0.00 \\
\hline State Bank of India & 0.32 & 0.00 \\
\hline Kotak Mahindra Bank & 0.56 & 0.00 \\
\hline ICICI Bank & 0.32 & 0.00 \\
\hline Axis Bank & 0.31 & 0.02 \\
\hline
\end{tabular}


Dr. Vishal Kumar, Ritu Rani

Performance Evaluation of Selected Banking Stocks Listed on Bombay Stock Exchange During Pre \& Post

Covid-19 Crisis

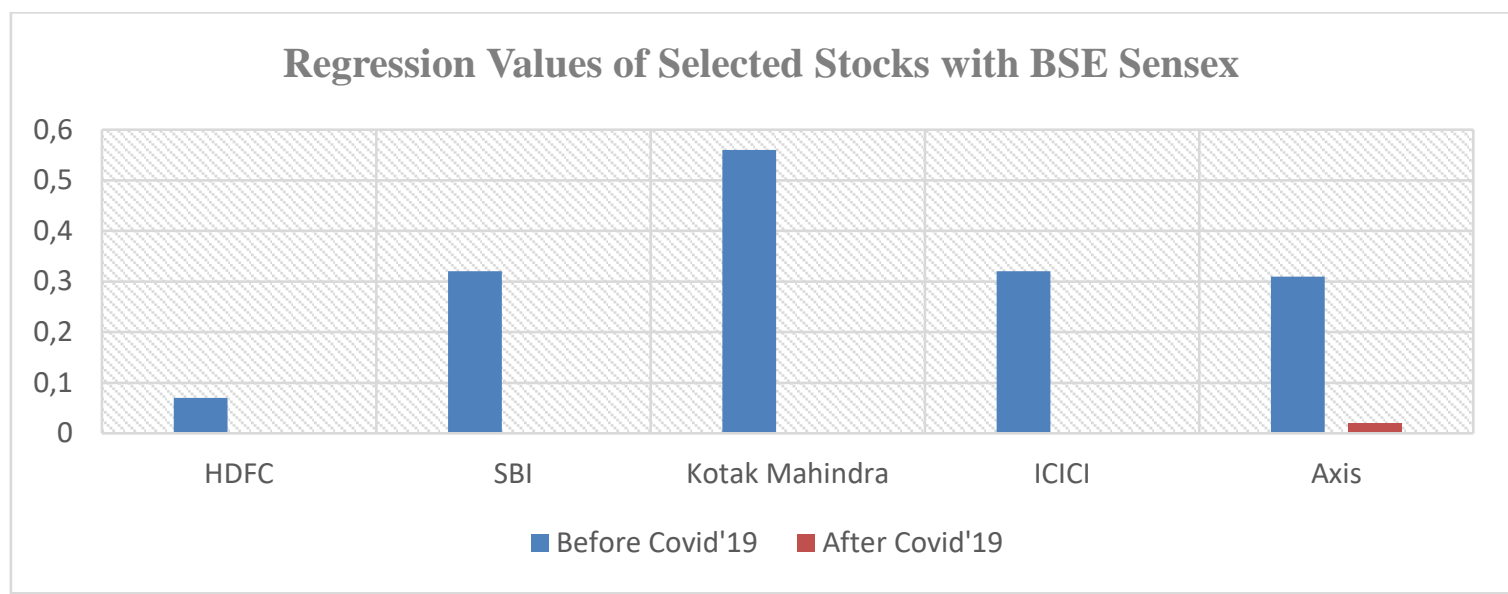

Interpretation: Except for Axis bank, the value of bank stocks is greater than the critical value during the pre-pandemic period. As a result, the null hypothesis is acceptable. Thus, except for Axis bank, the changes in the Sensex have had little impact on the stock exchange rates of banks during this period. The value of all bank shares would be lower than the critical threshold in the post-covid period. As a result, the null hypothesis is rejected. As such, it demonstrates that changes in the Sensex affect the prices of bank stocks. $\mathrm{H}_{0}$ : The exchange rate has no discernible effect on the chosen bank stocks.

Table 6: Showing the Regression Values of Selected Stocks Returns with Exchange Rate Motion

\begin{tabular}{|c|c|c|}
\hline Bank & Pre-Covid'19 & Post Covid'19 \\
\hline HDFC Bank & 0.229 & 0.00 \\
\hline State Bank of India & 0.003 & 0.00 \\
\hline Kotak Mahindra Bank & 0.612 & 0.412 \\
\hline ICICI Bank & 0.976 & 0.00 \\
\hline Axis Bank & 0.16 & 0.02 \\
\hline
\end{tabular}

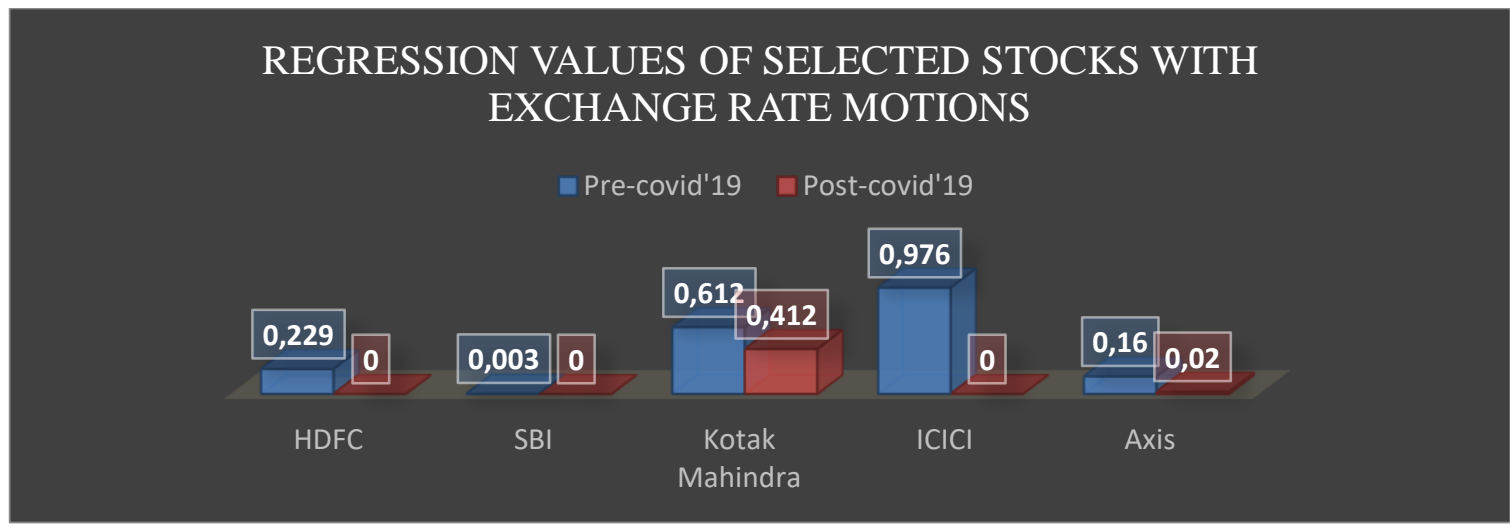

Interpretation: Exchange rate fluctuations have big effect on SBI's stock prices, as the attributes would be less than 0.05. However, for the remaining four banks, the null hypothesis is accepted, indicating no effect of the exchange rate change on bank stocks in the pre-period. Changes in the exchange rate have impacted the stock prices of Kotak Mahindra Bank following the pandemic, as the values are greater than 0.05. However, for the remaining four banks, the rejection of the null hypothesis, indicating that the exchange rate change did not affect bank stocks in the post-period. Therefore, the null hypothesis $\left(\mathrm{H}_{0}\right.$ : There is no discernible effect of FII mobility on the chosen bank shares) has been rejected here for four banks except Kotak Mahindra Bank. 
Dr. Vishal Kumar, Ritu Rani

Performance Evaluation of Selected Banking Stocks Listed on Bombay Stock Exchange During Pre \& Post

Covid-19 Crisis

Table 7: Showing the Regression Values of Selected Stocks Returns with FII Movement

\begin{tabular}{|c|c|c|}
\hline Bank & Pre-Covid'19 & Post Covid'19 \\
\hline HDFC Bank & 0.394 & 0.53 \\
\hline State Bank of India & 0.521 & 0.07 \\
\hline Kotak Mahindra Bank & 0.195 & 0.514 \\
\hline ICICI Bank & 0.784 & 0.24 \\
\hline Axis Bank & 0.684 & 0.12 \\
\hline
\end{tabular}

Interpretation: When each bank stock is regressed against the FII mobility factor for the pre-and post-period, the value exceeds the critical value of 0.05 at a $5 \%$ significance level. As a result, there is no discernible effect of alterations in FII activity on the chosen bank shares. $5^{\text {th }}$ Hypothesis Ho Changes in the G-Sec rate have no discernible effect on the chosen bank shares.

Table 8: Showing the Regression Values of Selected Stocks with G-Sec Coupon Rate

\begin{tabular}{|c|c|c|}
\hline Bank & Pre-Covid'19 & Post Covid'19 \\
\hline HDFC Bank & 0.683 & 0.04 \\
\hline State Bank of India & 0.049 & 0.06 \\
\hline Kotak Mahindra Bank & 0.001 & 0.419 \\
\hline ICICI Bank & 0.002 & 0.103 \\
\hline Axis Bank & 0.003 & 0.77 \\
\hline
\end{tabular}

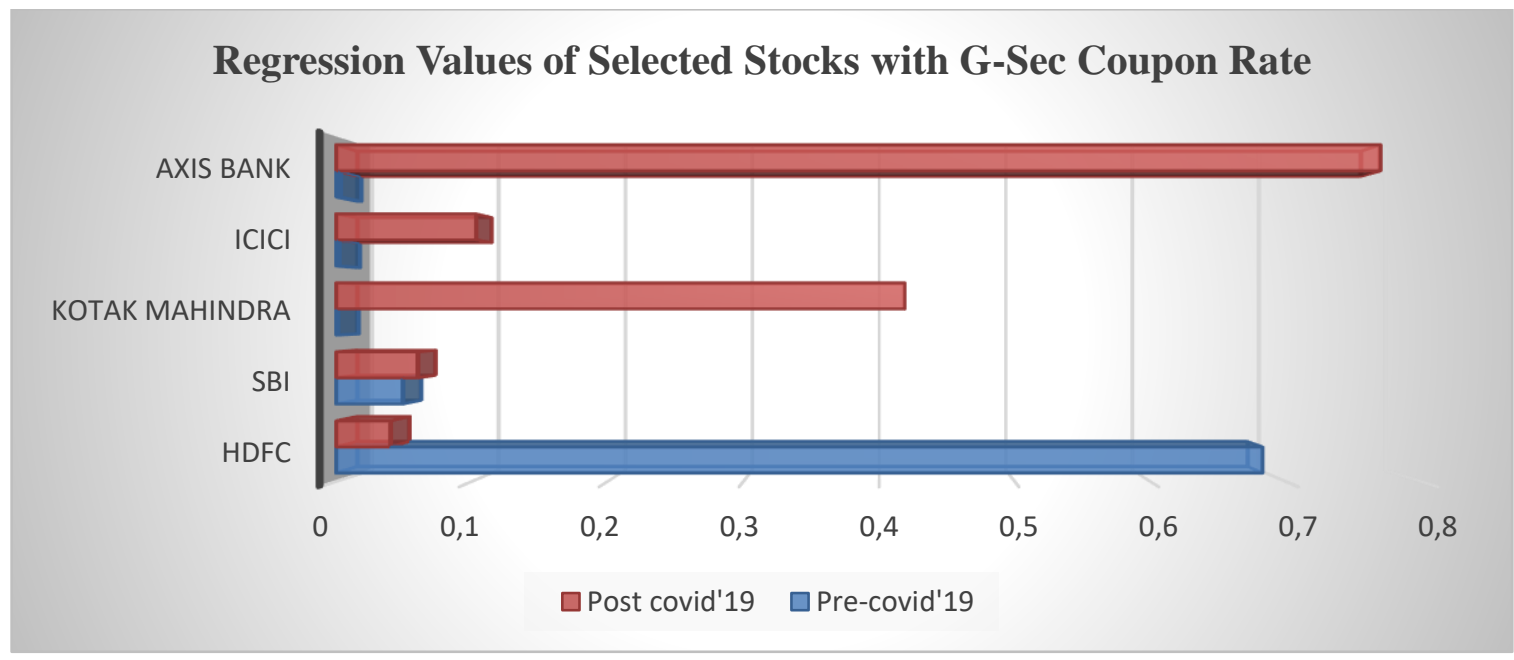

Interpretation: SBI and HDFC banks have a pre-period value greater than 0.05 . As a result, the null hypothesis has been adopted. Thus, during this period, changes in FII mobility have had little effect on stock prices, whereas they have impacted the share prices of the other three banks (less than 0.05). During the post-crisis period, the value of HDFC bank p 0.05 demonstrates that the G-Sec rate affects HDFC stock prices. However, there is no such effect on the remaining four bank stocks.

\section{Conclusion and Recommendations}

When each bank stock is regressed against the Economic factors during the pre-and post-pandemic period, the value is below 0.05 at a $5 \%$ level of significance, indicating that the said factors have significant impact on the selected bank stocks prices movements. Exchange rates also have a significant effect on SBI's stock price $(p=0.05)$. However, private banks demonstrate that the exchange rate had no effect on stock prices in the pre-pandemic period. Changes in exchange rates have had no discernible effect on the share prices of Kotak Mahindra Bank in the post-pandemic 


\section{Dr. Vishal Kumar, Ritu Rani}

Performance Evaluation of Selected Banking Stocks Listed on Bombay Stock Exchange During Pre \& Post Covid-19 Crisis

period ( $p>05$ ). In contrast, other banks demonstrate the impact of exchange rate changes on bank stocks in the post-pandemic period. When the value for each bank stock is regressed against the FII motion as during pre-pandemic and post-pandemic periods, the result is $(p>0.05)$ at the $5 \%$ level of significance, indicating that changes in FII movement have had no significant effect mostly on chosen bank stocks. SBI and HDFC have a pre-pandemic value of $\mathrm{p}>.05$ ). Changes in the FII movement have had little effect on stock prices but have affected the share prices of the other three banks, as the value found is less than 0.05 . The fact that the value of HDFC stock is lower than the critical value demonstrates that the G-Sec rate affects the price of HDFC stock. However, there is no such effect on the remaining four bank stocks. During a crisis, bank stocks experience extreme volatility, that is even greater than the market's volatility. During the first half of the study, before the crisis, there is a high correlation between the BSE Sensex and chosen share prices and a moderate, weak, and negative correlation with FII activity, the G-Sec rate, and the exchange rate, respectively. During the second quarter of the study, as stock prices improved, it was not clear whether all banks followed a similar pattern. The relationship between stock prices and economic variables varies significantly between banks. Changes in the BSE over the two-year study period have a massive effect on the chosen share prices, whereas alterations in the FII mobility have no impact on stock prices. The Sensex continues to exert a significant influence within second half of the years examined. Exchange rates and the G-Sec rate have affected the stocks of selected banks. During a crisis, investors become fearful, and the resulting uncertainty results in stock market volatility. The understanding of the banking sector's stock performance during a catastrophe can aid in prudent investment planning. It is clear from the above discussion that even a crisis results in increased volatility in banking stock prices relative to the SENSEX. Still, prices also correctly follow a steep fall.

\section{References}

> Al Rjoub, S. A., and H. Azzam. 2012. Financial crises, stock returns and volatility in an emerging stock market: The case of Jordan. Journal of Economic Studies 39 (2):178-211. doi: $10.1108 / 01443581211222653$.

> Al Rjoub, S. A. M. 2009. Business cycles, financial crises, and stock volatility in Jordan stock exchange. Social Science Electronic Publishing 31 (1):127-32. doi:10.2139/ssrn.1461819.

$>$ Ali, M., N. Alam, and S. A. R. Rizvi. 2020. Coronavirus (COVID-19) - An epidemic or pandemic for financial markets. Journal of Behavioral and Experimental Finance 100341.

> Apergis, N., and E. Apergis. 2020. Can the COVID-19 pandemic and oil prices drive the US Partisan conflict index? Energy Research Letters 1 (1):13144. doi:10.46557/001c.13144

> Battaglia, F., \& Gallo, A. (2015). Risk governance and Asian bank performance: An empirical investigation over the financial crisis. Emerging Markets Review, 25, 53-68

> Baranidharan, S. et al. (2020), "Linkages and Volatility Effect of Finance Companies Stock Price on BSE Finance Index", High Technology Letters, Vol. 26(8), pp. 1138-1152.

> Cave, Joshua, Kausik Chaudhuri, and Subal C. Kumbhakar. "Do banking sector and stock market development matter economic growth? Empirical Economics 59,4 (2020): 15131535

> Chen, Nai-Fu, Richard Roll, and Stephen A. Ross. "Economic forces and the stock market." Journal of business (1986): 383-403.

$>$ De Bondt, Werner FM, and Richard Thaler. "Does the stock market overreact? " The Journal of Finance 40, no. 3 (1985): 793-805.

> Dicle, M.F. and Reed, K. (2019), "Asymmetric Return Response to Expected Risk: Regulatory Response", Journal of Financial Regulation and Compliance, Vol. 27, No. 3, pp. 345-356.

> Fama, Eugene F. "The behaviour of stock-market prices." The journal of Business 38, no. 1 (1965): 34-105.

> Fernandez, P. (2019), "CAPM: An Absurd Model", Business Valuation Review, Vol. 34(1), pp. 4-23.

> Fiegenbaum, A. (1990), "Prospect Theory and the Risk-Return Association", Journal of Economic Behavior and Organization, Vol. 14, pp. 187-203. 


\section{Dr. Vishal Kumar, Ritu Rani}

Performance Evaluation of Selected Banking Stocks Listed on Bombay Stock Exchange During Pre \& Post Covid-19 Crisis

$>$ Han, H., and L. Ming. 2018. An overview of event study methodology. Statistics \& Decision 34 (13):66-71. DOI: 10.13546/j.cnki.tjyjc. 2018.13.015.

> Hoque, A. et al. (2020), "The Performance of Stock Portfolios: Evidence from Analysing Malaysia Case and Implication for Open Innovation", Journal of Open Innovation: Technology, Market and Complexity, Vol. 6(178), pp. 1-13.

$>$ Kalyan, B.N. and Maheshwari, Y. (2019). Assessment of Selected Securities in Media Industry, India. Econometric Modeling: Capital Markets Risk E-Journal, Vol. 8, No. 81. 